\title{
Organising professional support staff at higher education institutions: a multidimensional, continuous balancing act
}

\author{
Malin Ryttberg ${ }^{1}$ (D) Lars Geschwind $^{1}$ (D)
}

Received: 4 December 2019 / Accepted: 18 December 2020 / Published online: 11 January 2021

(C) The Author(s) 2021

\begin{abstract}
Centralisation is a recurrent theme when the organisational structure of contemporary higher education institutions is on the agenda. This may be in large part because of the unsolicited effects of decentralised organisational structures. The aim of this study is to explore how professional support staff at higher education institutions perceive the organisational structure of support and the rationales for this organising. An analytical framework based on the dichotomy of centralisation/decentralisation was applied in 18 interviews with professional support staff at one Dutch university and one Norwegian university. A common theme in the findings was the consciousness among the professional support staff that there is no one-size-fits-all solution for the organising of efficient and effective support. The issue of centralisation and standardisation was clearly on the agenda, but their focus was on the elements of a well-functioning support structure, not the specific organisational solution. The study also highlights the objection to the trend towards centralisation, and that some organisational changes may be too short sighted to be sustainable. From the perspective of the professional support staff, it can be concluded that organisational structure is a continuous balancing act based on dialogue between the academic and support staff.
\end{abstract}

Keywords Organising · Centralisation · Decentralisation · Standardisation · Professional support staff

\section{Introduction}

Administrative work in higher education institutions (HEIs) is regularly questioned by academics in terms of costs and a growing number of employees with support staff roles (Padró 2018;

Malin Ryttberg

ryttberg@kth.sec

1 School of Industrial Engineering and Management at KTH Royal Institute of Technology,

Stockholm, Sweden 
Schneijderberg and Merkator 2013). An immediate consequence of this critique is a pressure on the support staff to constantly become more efficient and effective (Kehm 2015). Support staff today constitute a significant category of employees in higher education institutions (HEIs). Their presence has increased in terms of both number and speciality, so that they now represent tasks and activities ranging from basic secretarial work and maintenance services to highly skilled tasks in, for example, internationalisation, business liaison and research support. This development may in part be explained by the missions and societal expectations placed on HEIs today (Bossu et al. 2018; Graham 2012; Ryttberg and Geschwind 2017; Stage and Aagaard 2019).

The multifaceted features of the professional support staff roles include that some of them work close to academics while others are physically more distant in the organisation. In this study, this issue is discussed by viewing centralisation and decentralisation of the support as alternative measures of achieving efficiency and effectiveness and thus a well-functioning support in HEIs. The aim of the study is to produce a close-up exploration of how professional support staff at two northern European HEIs perceive the way they are organised and what rationales there are for this organisation.

In the literature, the concepts of efficiency and effectiveness are often explained as the effects of the ideas of managerialism and New Public Management (NPM), which in turn are the result of steering ideals from the private sector. One example of the effects on HEIs is the increased emphasis on quality assurance and the accountability of managers (Amaral 2008; Deem et al. 2007; Geschwind et al. 2019). NPM constitutes a 'toolbox' from which to choose steering instruments, such as input/output controls, performance measurements and a general marketisation in which service users are treated as customers (Broucker et al. 2017; Maassen et al. 2017; Pinheiro et al. 2014).

The general ideas of efficiency and effectiveness may not be questioned by the support staff in HEIs. However, criticisms have been made of HEI's interpretations of the NPM concept with quantitative measurability as an important indicator of the accountability of managers. This approach clinches with the legalism strands of public administration where values such as accountability, equality and transparency are emphasised (Christensen et al. 2011; Curry 2014). One reaction to this critique has been the generation of a post-NPM paradigm, moving beyond the purely economic rationales (Christensen 2012; Marginson 2014). Examples are the emergence of steering theories that stress the interdependence of the internal collaboration between support staff and academics, implying a shared governance (Leach 2008).

The ideals of managerialism and NPM have obviously affected the entire organisation of HEIs, but in this study the focus is on the roles of professional support staff. Some of the previous literature has indicated that, in general terms, one effect on professional support staff has been the centralisation, standardisation and formalisation of support functions (Maassen et al. 2017). Other literature has focused on whether the increasingly managerial governance has had implications for academics' ideas about the university as a community of scholars with institutional autonomy and individual freedom. This phenomenon has in literature been described in terms of academics being loosely coupled from the central management level of HEIs. A belief is that this the new norm of a growing body of professional support staff has eclipsed the community of academics (Ginsberg 2011; Harris 2011). It may be claimed that the support staff periphery has expanded to the detriment of the 'academic heartlands' (Clark 1998; Schneijderberg and Merkator 2013). On the other hand, some research has indicated that large and complex public organisations, such as HEIs, can benefit from devoting additional resources to administration (Andrews et al. 2017). 
In summary, one assumption for his study is that the focus of the support staff is to give the best possible support to their HEIs. This is more important than whether the support is centralised or decentralised. Another assumption is indications in previous research of the professional support staffs' consciousness about having to tread carefully in the shaping of the support to gain legitimacy in relation to academics (Ryttberg 2020; Ryttberg and Geschwind 2017). This study contributes to the organisational analysis of HEIs by asking the professional support staff themselves how a well-functioning support may be organised. In previous research on this category of staff, a number of different designations have been used, such as 'higher education professionals' (Schneijderberg and Merkator 2013), 'third-space professionals' (Whitchurch and Law 2010), and 'non-academic managers 'or 'professionals' (Deem 1998; Rhoades and Sporn 2002). As 'professional' is central to these examples and support is the central task, we will in this study use the designation 'professional support staff' or simply 'support staff'.

\section{Organising professional support staff: An analytical lens}

One interpretation of Herbert Simon's seminal work Administrative Behaviour (Simon 1997) is that the theory of administration is concerned with how an organisation should be constructed and operated to accomplish its work efficiently and effectively or to get things done in relation to the objectives of the organisation. More specifically, the term 'efficient support' would imply any activity that rationally attempts to maximise the attainment of certain ends using scarce means or more output per unit input. However, to appraise the effectiveness and function of support staff better, these objectives must be stated in terms that are tangible with regard to the way they connect to the education and research missions of the HEI and to the expectations placed on the professional support staff. Ultimately, the organising of support can be described as a balancing act between the judgement of what competences are needed, the accurate level of service for a specific task and an acceptable cost for the specific support (Kivistö and Pekkola 2017). Added to these dimensions has to be an organisational perspective; is the specific support task optimised being organised centralised or decentralised?

The organising of professional services at HEIs is in this study approached in terms of a tension between centralisation and decentralisation. Principal stimuli for centralisation are the needs for responsibility, specialisation and coordination in an organisation. A current argument for centralisation is that universities have become massive, complex organisations with broadened expectations from the surrounding society, and that this development can only be led effectively by highly educated and specialised support staff positioned close to the management (Maassen et al. 2017). Another motive behind centralisation is the reduction of support costs arising from the unnecessary duplication of support activities in academic units, achieved by standardising the specific activity. The standardisation rationale includes increased transparency around specialisation and broadened access to specific technical and cognitive skills (Larson 1979). Another argument in favour of using standards is that they have an important coordinating function that can result in simplification, thereby potentially reducing the number of possibilities that need to be considered in the organising of specific support tasks. That said, some advocates of standardisation tend to emphasise that using standards can actually favour variation (Brunsson and Jacobsson 2000).

In the current study, standardisation refers to the extent to which the procedures for decision making, information provision and implementation are regularly occurring events that are legitimised by the HEI. Standardisation can be applied to rules for different circumstances, as well as to the role definitions and required qualifications for positions, titles, symbols, statuses 
and rewards. In the latter case, this could mean that the roles of support staff become depersonalised and independent of their personal features (Kivistö and Pekkola 2017; Maassen et al. 2017; Simon 1997).

Even though standardisation may imply that services are centralised, this is not the whole truth. Standardised tools can also be developed to be used locally in the organisation of HEIs. This has become even more obvious with the ongoing development of information technology (IT), through which standardisation can be taken to a new level. This is often referred to as 'digitalisation' when it creates new ways of organising work (Legner et al. 2017; Parviainen et al. 2017). In the context of this study, it means that standardised and digitalised support can be placed centrally at the HEI, but still perceived as close by the user, thanks to IT tools. The support might thus be organised in a 'oneto-many' relation, so that the actual support is constituted either by a human specialist or by IT systems designed for self-administration by the user (Susskind and Susskind 2015).

Decentralisation has two major stimuli. First, the fact that a very large portion of the information relevant to decision making originates at the operating and local level. Second, the separation of decisions from actions increases the time and labour costs of making, transmitting and communicating decisions (Simon 1997). Some measure of centralisation may be indispensable to securing the advantages of organisation, coordination, expertise and responsibility, but if the work is specialised, then [standardised] procedures have to be introduced to secure coordination among the members of a group. Successful use of specialisation to increase effectiveness implies either that no coordination is required among the specialised segments of the complete task or that this coordination can be achieved with the available techniques of interpersonal coordination. This is where decentralisation might be an option for organising.

Another argument for decentralisation is that standardisation, much like centralisation, is often seen as an unwelcome, unnecessary and harmful intrusion into a world of free, professionalised and distinct individuals and organisations who are wise enough to decide for themselves. Standardisation has also been criticised for not leaving any room for innovation (Brunsson and Jacobsson 2000; Simon 1997). In the context of HEIs, some professional support staff roles might today involve organising work in a more efficient way by standardising tasks that previously were included in academics' mandate. Centralisation is thus often equated with standardisation.

Even though centralisation aims at efficiency in terms of cost cutting, it may also create costs. For example, it may place lower-level decisions in the hands of highly paid personnel and lead to the repetition of functions, rendering subordinates superfluous. Consequently, some facility for coordination must be available, sometimes at a considerable cost. Moreover, centralisation leaves idle and unused the powerful coordinative capacity of humans available under a more decentralised form of organisation, substituting for it an interpersonal coordinative mechanism. Thus, for some support tasks, the decentralised solution might also be the most efficient one (Simon 1997).

Altogether it cannot be taken for granted what is the most efficient and effective organising of a well-functioning support at HEIs. The centralisation/ decentralisation dichotomy is in this study thus used as an analytical lens for the exploration of how professional support staff perceive the organisational structure of their support and the rationales behind this organising.

\section{Methods}

When organisational structure is at issue, there is a customary discussion of theories about centralisation and decentralisation that tends to result in identifying the pros and cons of each 
(Brunsson and Jacobsson 2000). Thus, these two concepts were points of departure for this study (Braun and Clarke 2006). However, a read-through of the literature on the organising of higher education revealed closely entangled themes, such as standardisation, managerialism, efficiency and effectiveness (Baltaru and Soysal 2018; Kivistö and Pekkola 2017; Maassen et al. 2017; Simon 1997).

The empirical strategy for the present study (Marshall and Rossman 2014) is qualitative, comprising semi-structured interviews with professional support staff at one Dutch university and one Norwegian university that took place in the autumn of 2017. These HEIs are selected based on their similarities; they are both prosperous universities with a stable position nationally and internationally and have not experienced any economic difficulties that could put costs for support staff on the agenda. In terms of governmental steering ideals, at the system level, in both Norway and the Netherlands, the characteristics are performance-based management with clear, stable and consistent goals, combined with the delegation of formal decisions to HEIs. In both countries, there are clear indications of a more contractual relationship between the government and HEIs (de Boer and van Vught 2016; Gornitzka and Larsen 2016). Both universities in this study have recently also undergone a reorganisation of the support services, which made them particularly interesting to study. In all the data from these two are weighed together to constitute a whole for the study.

On the basis of the intent to interview support staff with strategic roles and those who have an overview of the support services, 18 participants were suggested to us by the two HEIs. To reduce the risk of getting biased interview data from the HEIs the search started with browsing the HEIs' web pages to gather information about potential participants to suggest. They represented both central-university-level and faculty-level support service positions. The suggested participants all had either management or strategic advisory roles with the obvious risk of them being trained to give the organisations' officially correct answers. To reduce the risk of ready-made answers to our questions, we were clear in the early email correspondence about the purpose of the study without being too specific about the upcoming questions.

Another aspect of interviewing support staff with management or advisory roles was how they would discuss their roles as both close to the university management and their parallel dependence on the legitimacy of academics to fulfil their work. The general impression was that the participants quite generously elaborated their personal views on how they perceived the organising of the support services. A possible explanation may be that one of the researchers in this study has long experience as a professional support staff, which imbued to some level of trust during the interviews (Marshall and Rossman 2014) Table 1.

The interviews were conducted in Swedish or English, lasted for approximately an hour each and were taped and transcribed (Kvale and Brinkman 2009). The quotations were translated into English by the authors. The two main themes in the interview guide were how the participants would describe the organising of the support and what, in their view, constituted well-functioning support. The purpose here was for these questions to advance a close-up exploration of how these support staff perceived the organisational structure (Laksov et al. 2017) and the rationales behind the chosen solution.

Following transcription, the interviews were analysed within a framework of the concepts of centralisation and decentralisation in the design of efficient support. The aim was to determine the mechanisms that might account for what the data seemed to be showing. The observations from the interviews also aimed at refining an understanding of how theories about organising professional support staff might be interpreted (Laksov et al. 2017). The interviews were thematically coded and categorised using qualitative analysis software. The analysis 
Table 1 Title and Location of Interview Participants

Title of participants

Location in organisation

Advice worker, development issues

Director of organisational issues

Central

Senior adviser, education

Central

Head of evaluation department

Central

Head of controlling unit

Central

Dean

Administrative director

Central

Faculty

Faculty

Administrative director

Faculty

Vice president

Central

Director of education

Managing director $\times 2$

Central

Central

Secretary of the board

Central

Director of communications $\quad$ Central

Head of research policy Central

HR managers $\times 2 \quad$ Central

Head of finances \& concern controller $\quad$ Central

Managing director Faculty

Managing director Faculty

conducted was inspired by Braun and Clarke's (2006) six-step process of thematic analysis: (1) familiarisation with the data; (2) generation of initial codes; (3) search for expression of the pre-defined themes (centralised and de-centralised); (4) review of the themes in relation to the findings; (5) definition and labelling of the findings; and (6) production of report. Quotations were selected to illustrate the themes succinctly.

\section{Results}

With the aim of exploring how professional support staff perceive the organising of support services and the rationales behind this organisational structure, the findings were sorted by searching for the expressions of rationales for either a more centralised or more decentralised form of support.

\section{Rationales for centralisation: Standardisation and digitalisation}

Centralisation, standardisation and digitalisation were the main concepts that the participants used to describe the organising of support services at the two HEIs. A trend towards the centralisation of support staff was evident at both HEIs, but it was expressed in two different ways. At HEI(a), all support staff were employed centrally and then positioned either centrally at the HEI level or locally at a faculty or institutional level. At the HEI(b), support staff were employed at the central, faculty or department level. In the latter case, one participant described the situation thus: '.. . we have a reasonable combination of central and facultylevel staff, but it is our intention to steadily centralise more of our staff' (participant 1).

Closely connected to the participants' use of the designations of centralisation, standardisation and digitalisation was the rationale of cost cutting in the constant effort to ensure effective support. The message from one of the HEIs was that 'we look at our [faculty] department as the backbone of our university ...' (participant 9) and thus that any demands for cuts must be directed towards 
support. At the other HEI, a governmental demand for the debureaucratisation of HEIs was a characteristic feature. This has been interpreted as both a form of pressure and a need to cut support costs and has been used internally to legitimise centralisation.

Equalisation of support across the HEIs, to be achieved by standardisation, was another rationale behind the (re)organisation towards greater centralisation of support. The participants at both HEIs shared a frustration with the historical freedom of academics to solve problems in their own way without consulting support. Equal support was in turn equated with quality and efficiency within the support services.

A number of participants talked about digitalisation as a new tool for generating greater efficiency in support: ' $\ldots$ in the past, I think ... we had one central guideline, but everyone had their own interpretations ... whereas now we are turning towards more centralisation ... it's more university wide, one procedure' (participant 15). According to one participant, the latter is possible '... because of digitalisation' (participant 13). Standardisation as a means to efficiency was nothing new to the participants: ' $\ldots$ at an early stage, we realised the need to enhance, to streamline, to digitalise, to standardise ... they are all advantages on many levels because standardisation will lead to cost cuts ...' (participant 4). This was further emphasised by another participant, who said that '... many traditional support tasks with the role of ensuring a smooth machinery are made redundant, and their duties are taken over by digital solutions' (participant 5). 'For example, invoices ... we are only accepting digital invoicing' (participant 15). 'Efforts should be made to organise the whole HEI business in a comprehensive system, preferably by support through digital tools' (participant 3 ). According to another participant, '... well-functioning support is a machine that makes no mistakes and works around the clock ... which will lead to quality, both directly and indirectly' (participant 5).

Digitalisation could also be viewed as a manifestation of the division of labour at the HEIs. As expressed by one participant, '... [digitalisation] gives you more possibilities to work efficiently. People can go to the portals and get their questions fixed themselves through self-service elements and so on. So that makes it less obviously a decentralised organisation' (participant 13). One example of the far-reaching digitalisation at both HEIs is shown by the support routines concerning education. The registration of students was described as follows: 'If you are in a happy flow ... there isn't one person within the support services that actually has to do anything; it's all automated. It's easy: you can do it at night, you can do it remotely and you can do it here at the campus' (participant 13).

\section{Centralisation within limits: Critical voices}

Despite the general consensus about the concept of centralisation and that efforts for efficiency are a given in support work, the participants also expressed some critical opinions on the effects of centralisation, standardisation and digitalisation in relation to the missions of HEIs.

Here, centralisation has to be handled with care and sensitivity: 'We have reduced the support by $\mathrm{x} \%$... and should also have reviewed how we organise work ... but we are too busy bailing out the boat to have time to fix the leaks. If we are to handle the constantly occurring new challenges concerning quality, how can we not expand the support?' (participant 5).

Even though standardisation was not questioned in the interviews, one participant talked about the possible effects of digitalisation: 'I believe the turnover is less than one thinks. It does cost to digitalise. One might also think that it is a one-time investment, but the system has to be maintained and developed, and there will be a need for new solutions. ... But I realise that [digitalisation] also is a tool to disengage human resources for other duties' (participant 5). 
A second criticism concerned the relationship between the division of labour and digitalisation in its effects on the level of self-administration. Some participants said that they had already experienced how duties that had previously been tasks assigned to support staff were now self-administrated by academic staff: 'When you organise new digitalised systems, you have to be aware that the workload of the professor and the researchers will grow. Take travel, for instance. You generate costs when you travel. Now the professor has to do all the work because of design of the system' (participant 9).

A third criticism that came to the fore was that standardisation can be taken too far. One risk is that processes become too distant from the everyday work of academics: ' $\ldots$ the more centralised you get, the more distant [academic activity] becomes in some way. Work becomes more abstract and more indirect and focused on structures' (participant 5). This could mean support staff having inadequate knowledge and understanding of academic activities and academics perceiving support as unavailable. Among these critical voices may thus be discerned competence aspects. Some specialised support will function well when managed centrally at the HEI while other support might demand a face-to-face contact with academics.

A recurrent theme in the findings is furthermore that support via IT has come to stay. The big challenge at HEIs is now '... to keep on working with digitalisation of support duties, to standardise, and all the time to keep an eye on how this [digitalisation] benefits [academic] activities ...' (participant 1).

\section{The persistent need for local capacity}

The opposite of centralisation is decentralisation. Despite the fact that the rationale for the reorganising process at both HEIs was to centralise support, the participants quite consistently expressed the need to be physically available and close to the academics: 'Because we find it important to be close to the people to whom who we deliver services' (participant 13). 'The main objective of support is to develop the core business ... to ensure the best possible education [and] best possible research' (participant 3). 'We are [employed] to strengthen the core competences of [teachers and researchers], to enhance quality' (participant 1). The notion is thus that competence might be an aspect of the organisation structure of the professional services.

To ensure closeness to the academics, the solution at one HEI is for the support to be employed centrally but decentralised by being located at different faculties and departments. 'So in that sense, it's both [centralised and decentralised]. And we are very aware that the members of the scientific staff want services in their neighbourhood, and they want support to be around the corner, in their own corridor, in their own office' (participant 10).

By centralising and standardising some support, the intention is to free human resources for the more specialised types of support. IT is an example; at both HEIs, it was at first entirely centralised. The experiences arising from centralisation, however, showed that there also had to be some IT expertise situated locally, with knowledge about the local and possibly disciplinary context, who could give instant support.

Another competence related example is when one participant explained: '.. we decided that every department needed a teacher support officer ... His or her knowledge must encompass breadth and depth of the HEI: organisation structure, ongoing development at the HEI and other issues that might be relevant for a specific academic department ...' (participant 13). A principal reason for choosing decentralised support is to ensure that the support staff have knowledge and understanding of academic activities. It is of symbolic importance 'that you walk into the department, and professors can talk to you and everyone ... 
you'll be seen at the coffee machine, and they talk to you and you bring ...' (participant 16). This dialogue with the academics is further facilitated by support staff '.. who are able to have this discussion with scientific staff in such a way that they are taken seriously and are understood' (participant 10).

According to the findings, these considerations are closely related to the level of service needed, wished for and available at the HEI. The purpose of the service may be to provide answers to questions as rapidly as possible, but the service may also be intended to provide support from staff who are specialised in a specific area: 'I believe that we are very aware that there is a balancing act involved. It is important not to take away the academics power over education and research ... the dynamic is important. It is important for a dean to handle [his/ her] resources and steer the business to agree upon what support tasks should be standardised and where diversity can be accepted' (participant 8). This comes close to the prevailing discussion about efficiency and effectiveness in support work and the anxiety expressed by one participant about '... the organisation being too short sighted and too focused on utility ...' (participant 5). An HEI ' $\ldots$ is a very complex organisation, and even though we need a framework [a unified management], there has to be discretion for the deans to interact within their separate academic environment' (6). Awareness of this was also highlighted by one participant who said, '... I am enough of a part of the university culture to believe in the loose couplings we have in the sector. ... There is a good reason for using this as an excuse ... and not taking the streamlining philosophy too far. I'm not sure we can afford to lose the loose coupling ...' (participant 5). Required competences and service levels are thus two different aspects to take into consideration when organising support structures.

\section{Concluding discussion}

The aim of this study was to produce a close-up exploration of how professional support staff perceive their organisational structure and its rationales. An analytical lens based on the centralisation/decentralisation dichotomy was applied to the empirical data. That centralisation came up as the main orientation in the organising of the professional support staff did not come as a surprise considering the extensive literature on managerialism and NPM in higher education (Broucker et al. 2017). It is believed that centralisation, alongside the achievement of efficiency and effectiveness as objectives, has close connections to many professional support staff roles (Maassen et al. 2017). The main rationales, albeit entangled, for centralisation were cost cutting, efficiency, equal support, quality and digitalisation.

One conclusion from this study is that a principal way of achieving these goals is through the standardisation of repetitive and routine support tasks. Another conclusion is that this standardisation may be taken to a new level through the use of IT, that is, digitalisation. In this study, the reorganisation of professional support at both HEIs could help to explain why the concepts of centralisation, standardisation and digitalisation were at the participants' fingertips.

A major conclusion, however, is that centralisation has its limitations; it cannot provide a one-size-fits-all model for organising support. Every support task will require its own setting and combination of competences and levels of service. The organising of support and the broad palette of support tasks thus turn into a complex and entangled process of deciding what support is the most efficient and effective: centralised or decentralised. Some tasks suit a stricter, standardised and digitalised solution that can be managed by support functions centrally, locally by support staff or through self-administration by academics. Other forms of support may have to be adjusted to each academic's needs and must therefore be more 
flexible. A high level of flexibility might be viewed as directly proportional to a low level of centralisation and standardisation (Maassen et al. 2017), and vice versa.

According to the professional support staff in this study, one key to organising efficient support is a continuous flow of dialogue and collaboration between academics and support staff (see Fig. 1).

In this flow chart, decisions regarding the required competences and service levels for a specific task and what this would imply in terms of centralisation/decentralisation must be determined through dialogue.

A general conclusion from the current study is that the professional support do not question that their work should be examined to ensure that they provide an efficient and effective support. However, some staff voiced the opinion that efforts towards improved efficiency and effectiveness were being taken too far, leaving no resources for the development of the responsibilities of the support staff. Questions were also raised as to whether some organisational changes might be too short sighted to be sustainable, and about how an increased level of self-administration due to digitalisation related to the effectiveness of the HEI as a whole.

One contribution of this study is to provide a close-up examination of how professional support staff at contemporary HEIs perceive the organisational structure of their work in relation to theories about centralisation and decentralisation. A broad range of diverse professional support staff are required at HEIs for the multifaceted missions and expectations of contemporary HEIs (Baltaru and Soysal 2018; Graham 2012; Schneijderberg and Merkator 2013). However, a main contribution of the study is the critical opinions that the participants express concerning how to reach increased efficiency and efficacy at the HEIs. The combination of a belief in the organisations that centralisation is the primary solution and that cost cuts are directed towards professional support staff is a too simplified measure. The many different types of support services demand individual scrutinizing of how the support should be organised. In this shaping of the support needed, the staff must balance knowledge and understanding of the academic heartland with its norms and values (Sahlin and ErikssonZetterquist 2016). This may also be interpreted as counterforce to too much of centralisation and streamlining from the university management and thus also the academic communities getting too loosely coupled. This critique by the participants may be explained by that all participants had management positions being trained to express also critical views. In all the organising of support services clearly entails a multidimensional balancing act by the

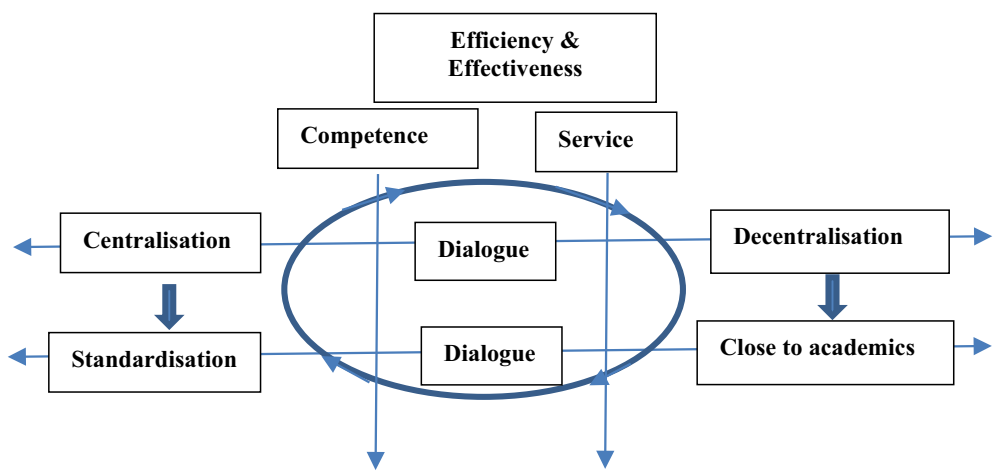

Fig. 1 Aspects of organising professional support staff at HEIs 
professional support staff in their attempts to contribute to the objectives of their HEI in an efficient and effective way.

Future studies might wish to go further and explore academics' view of the kinds of support they need, as well as what they believe constitutes an efficient and effective division of labour at HEIs with regard to the tasks of professional support staff and academics. This question also relates to the costs for support services that are acceptable in an HEI organisation.

Funding Open Access funding provided by Royal Institute of Technology.

Open Access This article is licensed under a Creative Commons Attribution 4.0 International License, which permits use, sharing, adaptation, distribution and reproduction in any medium or format, as long as you give appropriate credit to the original author(s) and the source, provide a link to the Creative Commons licence, and indicate if changes were made. The images or other third party material in this article are included in the article's Creative Commons licence, unless indicated otherwise in a credit line to the material. If material is not included in the article's Creative Commons licence and your intended use is not permitted by statutory regulation or exceeds the permitted use, you will need to obtain permission directly from the copyright holder. To view a copy of this licence, visit http://creativecommons.org/licenses/by/4.0/.

\section{References}

Amaral, A. (2008). Transforming higher education. In A. Amaral, I. Bleiklie, \& C. Musselin (Eds.), From governance to identity: Higher education dynamics, vol 24 (pp. 81-94). Dordrecht: Springer.

Andrews, R., Boyne, G., \& Mostafa, A. M. S. (2017). When bureaucracy matters for organizational performance: Exploring the benefits of administrative intensity in big and complex organizations. Public Administration, 95(1), 115-139.

Baltaru, R.-D., \& Soysal, Y. N. (2018). Administrators in higher education: Organizational expansion in a transforming institution. Higher Education, 76(2), 213-229.

Bossu, C., Brown, N., \& Warren, V. (2018). Professional and support staff in higher education: An introduction. In C. Bossu \& N. Brown (Eds.), Professional and support staff in higher education: University development and administration (pp. 1-8). Singapore: Springer.

Braun, V., \& Clarke, V. (2006). Using thematic analysis in psychology. Qualitative Research in Psychology, $3(2), 77-101$.

Broucker, B., De Wit, K., \& Verhoeven, J. C. (2017). Higher education research: Looking beyond new public management. In J. Huisman \& M. Tight (Eds.), Theory and Method in Higher Education Research (pp. 2138). Emerald Publishing Limited.

Brunsson, N., \& Jacobsson, B. (2000). A world of standards. Oxford: Oxford University Press.

Christensen, T. (2012). Post-NPM and changing public governance. Meiji Journal of Political Science and Economics, 1(1), 1-11.

Christensen, R. K., Goerdel, H. T., \& Nicholson-Crotty, S. (2011). Management, Law, and the pursuit of the public good in public administration. Journal of Public Administration Research and Theory, 21(suppl_1), i125-i140. https://doi.org/10.1093/jopart/muq065.

Clark, B. R. (1998). Creating entrepreneurial universities: Organizational pathways of transformation. issues in higher education. New York: Pergamon press.

Curry, D. (2014). Trends for the future of public sector reform: A critical review of future-looking research in public administration. The COCPUs project, EU FP-7. www.cocops.eu.

de Boer, H., \& van Vught, F. (2016). Higher education governance in the Netherlands: From a Janushead to a Trimurti. In N. Cloete, L. Goedegebuure, Å. Gornitzka, J. Jungblut, \& B. Stensaker (Eds.), Pathways through higher education research: A Festschrift in honour of Peter Maassen (pp. 25-32). Oslo: University of Oslo.

Deem, R. (1998). 'New managerialism' and higher education: The management of performances and cultures in universities in the United Kingdom. International Studies in Sociology of Education, 8(1), 47-70.

Deem, R., Hillyard, S., \& Reed, M. (2007). Knowledge, higher education, and the new managerialism: The changing management of UK universities. Oxford: Oxford University Press.

Geschwind, L., Hansen, H. F., Pinheiro, R., \& Pulkkinen, K. (2019). Governing performance in the Nordic universities: Where are we heading and what have we learned? In R. Pinheiro, L. Geschwind, H. Foss 
Hansen, \& K. Pulkkinen (Eds.), Reforms, organizational change and performance in higher education (pp. 269-299). Cham: Palgrave Macmillan.

Ginsberg, B. (2011). The fall of the faculty. Oxford: Oxford University Press.

Gornitzka, Å., \& Larsen, I. M. (2016). The paradoxical drama of university change: Four cases of moving the unmovable. In N. Cloete, L. Goedegebuure, Å. Gornitzka, J. Jungblut, \& B. Stensaker (Eds.), Pathways through higher education research: A Festschrift in honour of Peter Maassen (pp. 18-24). Oslo: University of Oslo.

Graham, C. (2012). Transforming spaces and identities: The contributions of professional staff to learning spaces in higher education. Journal of Higher Education Policy and Management, 34(4), 437-452.

Harris, D. (2011). Managerialism and myth: The legitimacy of management in higher education and the consequences of its decline. Power and Education, 3(2), 117-127.

Kehm, B. M. (2015). The influence of new higher education professionals on academic work. In U. Teichler \& W. Cummings (Eds.), Forming, Recruiting and Managing the Academic Profession. The Changing Academy - The Changing Academic Profession in International Comparative Perspective, vol 14 (pp. 101-111). Cham:Springer: Springer. https://doi.org/10.1007/978-3-319-16080-1_6.

Kivistö, J., \& Pekkola, E. (2017). Quality of administration in higher education. Stockholm: SUHF.

Kvale, S., \& Brinkman, S. (2009). Interviews: Learning the craft of qualitative interviewing. London: Sage.

Laksov, K. B., Dornan, T., \& Teunissen, P. W. (2017). Making theory explicit: An analysis of how medical education research(ers) describe how they connect to theory. BMC Medical Education, 17(1), 18.

Larson, M. L. (1979). The rise of professionalism. Pediatrics, 63(3), 490-490.

Leach, W, D. (2008). Shared governance in higher education: Structural and cultural responses to a changing national climate. https://doi.org/10.2139/ssrn.1520702

Legner, C., Eymann, T., Hess, T., Matt, C., Böhmann, T., Drews, P., \& Ahlemann, F. (2017). Digitalization: Opportunity and challenge for the business and information systems engineering community. Business \& Information Systems Engineering, 59(4), 301-308.

Maassen, P., Gornitzka, Å., \& Fumasoli, T. (2017). University reform and institutional autonomy: A framework for analysing the living autonomy. Higher Education Quarterly, 71(3), 239-250.

Marginson, S. (2014). Higher education as a public good in a marketized east Asian environment. In A. Yonezawa, Y. Kitamura, A. Meerman, \& K. Kuroda (Eds.), Emerging international dimensions in east Asian higher education (pp. 15-33). Dordrecht: Springer.

Marshall, C., \& Rossman, G. B. (2014). Designing qualitative research. Thousand Oaks, CA: Sage.

Padró, F. F. (2018). Preface. In C. Bossu \& N. Brown (Eds.), Professional and Support Staff in Higher Education (pp. v-xxii). Singapore: Springer. https://doi.org/10.1007/978-981-10-6858-4.

Parviainen, P., Tihinen, M., Kääriäinen, J., \& Teppola, S. (2017). Tackling the digitalization challenge: How to benefit from digitalization in practice. International Journal of Information Systems and Project Man agement, 5(1), 63-77.

Pinheiro, R., Geschwind, L., \& Aarrevaara, T. (2014). Nested tensions and interwoven dilemmas in higher education: The view from the Nordic countries. Cambridge Journal of Regions, Economy and Society, 7(2), 233-250.

Rhoades, G., \& Sporn, B. (2002). New models of management and shifting modes and costs of production: Europe and the United States. Tertiary Education \& Management, 8(1), 3-28.

Ryttberg, M. (2020). Legitimacy Dynamics of Professional Support Staff at Higher Education Institutions. Higher Education Policy. https://doi.org/10.1057/s41307-020-00206-w.

Ryttberg, M., \& Geschwind, L. (2017). Professional support staff at higher education institutions in Sweden: Roles and success factors for the job. Tertiary Education and Management, 23, 334-346.

Sahlin, K., \& Eriksson-Zetterquist, U. (2016). Collegiality in modern universities-the composition of governance ideals and practices. Nordic Journal of Studies in Educational Policy, 2-3. https://doi.org/10.3402/nstep.v2. 33640 .

Schneijderberg, C., \& Merkator, N. (2013). The new higher education professionals. In B. Kehm \& U. Teichler (Eds.), The academic profession in Europe: New tasks and new challenges (pp. 55-92). Dordrecht: Springer.

Simon, H. A. (1997). Administrative behavior: A study of decision-making. New York: Simon and Schuster.

Stage, A, K., \& Aagaard, K. (2019). Danish universities under transformation: Developments in staff categories as indicator of organizational change. Higher Education 78, 629-652.

Susskind, R., \& Susskind, D. (2015). The future of the professions: How technology will transform the work of human experts. Oxford: Oxford University Press.

Whitchurch, C., \& Law, P. (2010). Optimising the potential of third space professionals in UK higher education. London: Leadership Foundation for Higher Education Retrieved from http:/www.lfhe.ac.uk/research/ smallprojects/ioefinalreport.doc.

Publisher's Note Springer Nature remains neutral with regard to jurisdictional claims in published maps and institutional affiliations. 